\title{
Dictyostelium as a model to assess site-specific
}

\section{ADP-ribosylation events}

Anna-Lena Kolb, Duen-Wei Hsu, Ana B. A. Wallis, Seiji Ura, Alina Rakhimova, Catherine J. Pears and Nicholas D. Lakin

Department of Biochemistry, University of Oxford, South Parks Road, Oxford, UK

Tel: (+44) 1865613244

Email: nicholas.lakin@bioch.ox.ac.uk

Running title: Studying ADP-ribosylation in Dictyostelium

Keywords: ADP-ribosylation; PARP; ADP-ribosyltransferase; Dictyostelium; DNA Repair 


\section{ABSTRACT}

The amoeba Dictyostelium discoideum is a single cell organism that can undergo a simple developmental programme, making it an excellent model to study of the molecular mechanisms of cell motility, signal transduction and cell-type differentiation. A variety of human genes that are absent or show limited conservation in other invertebrate models have been identified in this organism. This includes ADP-ribosyltransferases, also known as PolyADP-ribose polymerases (PARPs), a family of proteins that catalyse the addition of single or poly-ADP ribose moieties onto target proteins. The genetic tractability of Dictyostelium and its relatively simple genome structure makes it possible to disrupt PARP gene combinations, in addition to specific ADP-ribosylation sites at endogenous loci. Together, this makes Dictyostelium an attractive model to assess how ADP-ribosylation regulates a variety of cellular processes including DNA repair, transcription and cell type specification. Here we describe a range of techniques to study ADP-ribosylation in Dictyostelium, including analysis of ADP-ribosylation events in vitro and in vivo, in addition to approaches to assess the functional roles of this modification in vivo.

\section{INTRODUCTION}

Studying a variety of biological phenomena in relatively simple genetic model organisms has been instrumental in providing novel concepts and insights into how these processes work in humans. However, whilst ADP-ribosyltransferases (ARTs) that catalyse mono- and polyADP-ribosylation are present in a variety of eukaryotic model organisms, in many instances the complement of these enzymes is not as extensive as in humans [1,2]. This makes it difficult to use these powerful experimental systems to unravel the complexities of how a variety of ARTs converge to regulate different biological processes. For example, DNA damage responsive ARTs are absent in yeast, the most commonly used genetic model to study DNA repair, prohibiting the use of this experimental system to assess how ADPribosylation regulates DNA repair and other processes. 
Of the 17 human ARTs identified PARP1, PARP2, PARP5a (Tankyrase 1) and PARP5b (Tankyrase 2) catalyse poly-ADP-ribose chains. All other ARTs catalyse mono-ADPribosylation, with the exception of PARP9 and PARP13, which are inactive [3]. Recently, we and others found that vertebrate DNA repair factors lost in certain invertebrate models are unusually conserved in the genetically tractable amoeba Dictyostelium, including ARTs that catalyse mono-ADP-ribosylation [4-12]. Similar to humans, two ARTs are required for tolerance of cells to DNA single strand breaks (SSBs), whilst a third that catalyses monoADP ribosylation (Adprt1a) is required to promote repair of DNA double strand breaks (DSBs) by NHEJ $[11,12,10,13]$. The mechanistic basis of how ARTs regulate the repair process is similarly conserved, with a variety of ADP-ribose interaction domains being required to promote the assembly of repair factors at DNA lesions [14,12,15]. This striking conservation of ART function in the Dictyostelium DNA damage response suggests that this organism will be a useful model to study how ADP-ribosylation regulates other cellular processes.

Dictyostelium is a soil-dwelling single celled haploid eukaryote that feeds on bacteria. However, if the food source becomes depleted cells aggregate to undergo a series of carefully programmed differentiation steps that generate a multi-cellular fruiting body of spores supported by a stalk of vacuolated cells [16]. This simple developmental programme has resulted in Dictyostelium being a much-used model to study cell fate and differentiation, chemotaxis, cell motility and signal transduction. This has led to the development of a number of techniques that makes this organism a powerful system to study processes regulated by ADP-ribosylation. For example, large numbers of cells can be grown easily in the laboratory, providing significant amounts of material for cell biology, biochemical or proteomics analysis. The fully sequenced and annotated genome and associated resources (dictybase.org), in addition to the haploid nature of the Dictyostelium genome, makes gene disruption and replacement strategies by targeted-homologous recombination relatively straightforward. Additionally, libraries of Dictyostelium mutants can be generated easily to 
employ in genetic or chemical screens [17-21]. The relatively simple genome organisation of Dictyostelium also makes it possible to genetically alter certain genes that are challenging to manipulate in vertebrates. For example, the high copy number arrays of histone genes in vertebrates makes it difficult to disrupt specific sites in these genes to assess how histone ADP-ribosylation events regulate a variety of cellular processes in vivo. In contrast, Dictyostelium contain single copy histone genes [22,23], making this approach tractable [13].

Here we describe techniques to study ADP-ribosylation in Dictyostelium, including the analysis of ADP-ribosylation events in vitro and in vivo, in addition to gene disruption strategies to assess the functional roles of ARTs and ADP-ribosylation in vivo. Given the expertise of our laboratory, we concentrate on the use of these assays to assess the role of ARTs and histone ADP-ribosylation in DNA repair. However, given Dictyostelium is an established model to study a variety of pathways including gene expression, cell type specification and cell motility, these techniques can equally be applied to study how ADPribosylation regulates processes other than genome stability.

\section{MATERIALS}

All solutions are made in double distilled water (or otherwise purified water).

2.1 Buffers, solutions and general materials

1. 10x Phosphate-buffered saline (PBS): $1.37 \mathrm{M} \mathrm{NaCl}, 27 \mathrm{mM} \mathrm{KCl}, 100 \mathrm{mM} \mathrm{Na}_{2} \mathrm{HPO}_{4}, 18 \mathrm{mM}$ $\mathrm{KH}_{2} \mathrm{PO}_{4},(\mathrm{pH} 7.4)$

2. 1X Phosphate-buffered saline with Tween20 (PBST): Dilute 10xPBS 10-fold in water, add 0.1\% Tween® 20, (pH 7.4). 
3. 10x Tris-buffered Saline (TBS): $24.8 \mathrm{mM}$ Tris- $\mathrm{HCl}, 1.37 \mathrm{M} \mathrm{NaCl},(\mathrm{pH} 7.4)$.

4. 1x Tris-buffered Saline with Tween20 (TBST): Dilute 10xTBS 10-fold in water, add 0.1\% Tween® 20, $(\mathrm{pH} 7.4)$.

5. Blasticidin S: $10 \mathrm{mg} / \mathrm{mL}$ stock, made up in water. Stored at $-20^{\circ} \mathrm{C}$. Final concentration for selection is $10 \mu \mathrm{g} / \mathrm{mL}$.

6. $\mathrm{H} 50$ buffer: $50 \mathrm{mM} \mathrm{KCl}, 20 \mathrm{mM}$ Hepes, $10 \mathrm{mM} \mathrm{NaCl}, 5 \mathrm{mM} \mathrm{NaHCO}_{3}, 1 \mathrm{mM} \mathrm{NaH}_{2} \mathrm{PO}_{4} \cdot \mathrm{H}_{2} \mathrm{O}$, $1 \mathrm{mM} \mathrm{MgSO}_{4} \cdot 7 \mathrm{H}_{2} \mathrm{O}(\mathrm{pH} 7.0)$. Filter sterilise. For long term storage keep at $-20^{\circ} \mathrm{C}$.

7. HL5: $5 \mathrm{~g} / \mathrm{L}$ proteose peptone, $5 \mathrm{~g} / \mathrm{L}$ thiotone $E$ peptone, $10 \mathrm{~g} / \mathrm{L}$ glucose, $5 \mathrm{~g} / \mathrm{L}$ yeast extract, $0.35 \mathrm{~g} / \mathrm{L} \mathrm{Na} \mathrm{HPO}_{4} .7 \mathrm{H}_{2} \mathrm{O}, 0.35 \mathrm{~g} / \mathrm{L} \mathrm{KH}_{2} \mathrm{PO}_{4}, 0.05 \mathrm{~g} / \mathrm{L}$ dihydrostreptomycin-sulfate $(\mathrm{pH} 6.5)$.

8. $\mathrm{KK} 2: 19 \mathrm{mM} \mathrm{KH}_{2} \mathrm{PO}_{4}, 3.6 \mathrm{mM} \mathrm{K}_{2} \mathrm{HPO}_{4}$.

9. Mounting media containing 4',6-diamidino-2-phenylindole (DAPI).

10. NEB-IF: $10 \mathrm{mM}$ PIPES (pH 6.8), $300 \mathrm{mM}$ Sucrose, $3 \mathrm{mM} \mathrm{MgCl}$, $20 \mathrm{mM} \mathrm{NaCl}, 0.5 \%$ Triton, use whilst cold, store at $4^{\circ} \mathrm{C}$ and use within $24 \mathrm{~h}$.

11. NEB-HAE: $50 \mathrm{mM}$ Tris $\mathrm{pH} 8.0,10 \mathrm{mM} \mathrm{NaCl}, 3 \mathrm{mM} \mathrm{MgCl} 2,3 \mathrm{mM} \mathrm{CaCl} 2,0.5 \mathrm{M}$ sorbitol, 0.6\% Triton X 100, Complete protease inhibitor cocktail (EDTA-free, Roche, 2 mini tablets per $10 \mathrm{~mL}$ ), phosphatase inhibitor cocktail 2 and 3 (Sigma, $100 \mu$ from each cocktail for $10 \mathrm{ml}$ of NLB), $10 \mu \mathrm{M}$ Benzamide, and $200 \mu \mathrm{M}$ DEA. 
12. Nuclear Lysis buffer (NLB): 50 mM Hepes, $150 \mathrm{mM} \mathrm{NaCl}, 1 \mathrm{mM}$ EDTA, Phosphatase inhibitor cocktail 2 and 3 (Sigma, $100 \mu$ from each cocktail for $10 \mathrm{ml}$ of NLB), Complete

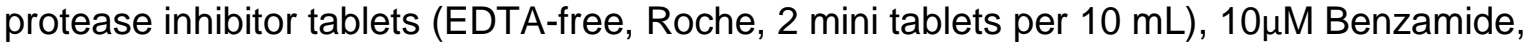
$200 \mu \mathrm{M}$ DEA.

13. Nuclear Lysis buffer* $\left(\right.$ NLB $\left.^{\star}\right)$ : NLB supplemented with $10 \mu \mathrm{M}$ Benzamide and $200 \mu \mathrm{M}$ DEA.

14. SDS loading buffer: $25 \mathrm{mM}$ Tris (pH 6.8), 10\% Glycerol, $2 \%$ SDS, $0.1 \%$ bromophenol blue, $100 \mathrm{mM}$ Dithiothreitol. Aliquot and store at $-20^{\circ} \mathrm{C}$.

15. SM Agar: $1 \%$ peptone, $56 \mathrm{mM}$ glucose, $0.1 \%$ yeast extract, $16 \mathrm{mM} \mathrm{KH}_{2} \mathrm{PO}_{4}, 5.5 \mathrm{mM}$ $\mathrm{K}_{2} \mathrm{HPO}_{4} .3 \mathrm{H}_{2} \mathrm{O}, 4 \mathrm{mM} \mathrm{MgSO}$, $1.7 \%$ agar (Autoclaved). Pour into Petri dishes to agar depth of about $1.5 \mathrm{~cm}$. Keep the Petri dish lid off the plate whilst the agar sets to avoid the condensation.

16. BugBuster Protein extraction reagent (EMD Millipore): Recommended for gentle extraction of proteins from bacteria to avoid contamination with chromosomal DNA.

17. 1x ADP-ribosylation buffer: $50 \mathrm{mM}$ Tris- $\mathrm{HCl}$ pH8, $75 \mu \mathrm{M} \mathrm{NAD+}, 2 \mathrm{mM} \mathrm{MgCl}$.

\subsection{Antibodies and ADP binding reagents}

1. Antibody solution for IF: Serum from the animal in which the secondary antibody was raised is diluted to $10 \%$ in $1 \times$ TBS. Prior to preparing the antibody solution, centrifuge the serum at full speed for 3 minutes to removes debris which appears as a pellet and surface scum. The antibody solution should be made with the serum appearing between the two debris fractions. 
2. Primary antibody for western blotting: Diluted either in $1 \times$ PBST or in $5 \%$ milk in $1 \times$ TBST for western blotting. We have successfully used the following antibodies: $\alpha-\gamma H 2 A X$ (Abcam, ab11174) - immunofluorescence and Western blot (1:1000); a-poly(ADP-ribose) (PAR; polyclonal, Trevigen, 4336-BPC-100) - immunofluorescence (1:300), Western blot (1:1000); a-H3 (Abcam, ab12079-100) - Western blot (1:2000); a-Actin (sc-1615) - Western blot (1:1000); HRP-conjugated Streptavidin (Sigma, RPN1231)- Western Blot (1:4000); $\alpha$-His (Sigma, SAB1305538) - Western Blot (1:2000).

3. ADP-binding reagents: Anti-ADP-ribose binding reagents are useful for the detection of ADP-ribosylated proteins on membranes or on fixed cells, similar to antibody-based western blotting and immunofluorescence. Poly-ADP-ribose binding reagent (Millipore; MABE1031) and pan-ADP-ribose binding reagent (Millipore; MABE1016) are used 1:1000 diluted in 5\% milk in 1xTBST.

4. Secondary antibodies and other detection agents for Western blotting: Antibodies conjugated to a fluorescent tag (e.g. TRITC or FITC) for immunofluorescence (diluted 1:80 in antibody solution) or to horseradish peroxidase for Western blotting (diluted 1:5000 in 1x PBST or in 5\% milk in 1xTBST). HRP-conjugated Streptavidin (Sigma; diluted 1:4000 in 1x PBST).

2.3 Cells and cell culture

1. Dictyostelium discoideum Ax2 cells: (available from the Dictyostelium stock centre via dictyBase.org), are grown either in shaking suspension or adhered to the surface of a plastic dish in $\mathrm{HL} 5$ medium at $22^{\circ} \mathrm{C}$. Genetically modified strains are grown in presence of Blasticidin $(5-10 \mu \mathrm{g} / \mathrm{mL})$. 
2. Klebsiella aerogenes (Ka) suspension: Grow lawn of Ka on SM agar plate. Scrape some bacteria using $200 \mu$ pipette tip into $1 \mathrm{~mL}$ of $\mathrm{KK} 2$ and vortex to remove clumps. Bacteria available from Dictyostelium stock centre (dictyBase.org).

\subsection{Plasmids}

1. pLPBLP or equivalent plasmid containing blasticidin $S$ resistance cassette: The pLPBLP plasmid can be obtained from the stock centre accessed via dictyBase.org. This plasmid can be used to generate Dictyostelium disruption strains by insertion of DNA sequences of the gene of interest flanking the blasticidin $\mathrm{S}$ resistance cassette.

2. pJET 1.2: (CloneJET PCR Cloning Kit, Thermo Scientific) is used for subcloning.

3. pDXA-3C: Obtained from the stock centre accessed via dictyBase.org. This plasmid is used as extrachromosomal expression vector under control of the actin 15 promoter, carrying a Cterminal c-myc tag and a neomycin resistance cassette [24,25].

4. pREP: A plasmid for co-transformation with pDXA-3C expression vector. The plasmid can be obtained from the stock centre accessed via dictyBase.org.

\subsection{Equipment}

1. Biorad $0.1 \mathrm{~cm}$ Gene pulser cuvette (product code: $165-2089$ )

2. Biorad Gene Pulser Xcell electroporator

3. Vacuum-Gel dryer

4. Parafilm

5. Phosphorimager 
6. Microscope: 1X71 Olympus microscope at 100X magnification with an Olympus lens and immersion oil (Lenzol): C10600-10B-H Hamamatsu Photonics camera with HClmage Acquisition (Hamamatsu Photonics) image software, or equivalent.

7. PCR machine

8. Western Blot developer machine

9. Western blotting: Biorad Mini-PROTEAN® 3 Cell system or equivalent.

10. X-Ray films

\section{METHODS}

\subsection{ADP-ribosylation assays in vitro}

Analysis of ADP-ribosylation in vitro is able to define the type of modification catalysed by a given ART (e.g. poly- or mono-ADP-ribosylation), in addition to identifying potential sites on substrates modified by these enzymes [26]. Findings from these approaches can then guide the analysis of ADP-ribosylation events in vivo. Whilst these approaches have been developed during the study of human ARTs, they are transferable to the analysis of ARTs from other organisms, including Dictyostelium [13]. Given ARTs ADP-ribosylate themselves, the type of modification catalysed can be identified by assessing the auto-modification status of ARTs following incubation with NAD+, in addition to sheared DNA that is a requirement for activation of DNA damage responsive ARTs [3]. To identify potential substrates a similar workflow is employed, with the exception that reactions additionally include the putative substrate being analysed.

\subsubsection{ART Auto-ADP-ribosylation assays}

These assays involve incubating a purified recombinant ART in a reaction buffer containing $\mathrm{NAD}^{+}$and sheared DNA fragments containing DNA breaks that activate the activity of the enzyme. Inclusion of biotin-conjugated or radioactive $\mathrm{NAD}^{+}$allows detection of the automodified ART following SDS-PAGE and Western blotting or autoradiography respectively. 
Detection of ART Auto-ribosylation using Streptavidin conjugated NAD

1. Recombinant His-tagged ART is expressed and purified from bacteria using standard protocols. In order to minimise activation of ART by bacterial DNA released by lysis procedures such as sonication, we recommend a gentler lysis procedure using BugBuster.

2. Set up a $20 \mu \mathrm{l}$ reaction on ice in 1x ADP-ribosylation buffer including $25 \mu \mathrm{M}$ biotinylated $\mathrm{NAD}^{+}$either with or without $5 \mu \mathrm{g} / \mathrm{ml}$ of sheared salmon sperm DNA to activate the enzymatic activity of the ART. Add a final concentration of $1 \mu \mathrm{M}$ recombinant ART to start the reaction.

3. Incubate the mixture at room temperature for 30 minutes.

4. Quench the reaction by adding $20 \mu \mathrm{l} 2 \mathrm{xSDS}$ loading buffer and boil the mixture for 5 minutes (see Note 2).

5. Resolve the samples by SDS-PAGE using gels with the appropriate concentration of acrylamide depending on the molecular weight of the ART. For ARTs between 80-100 kDa an $8 \%$ gel is used. Transfer the proteins from the gel onto a PVDF membrane using standard Western blotting procedures.

6. Block the membrane with in 1x PBST containing 1\% BSA for 2 hours at room temperature.

7. Wash the membrane 3 times for 10 minutes with 1 xPBST.

8. Incubate the membrane with a 1:4000 dilution of HRP-conjugated Streptavidin in $1 \mathrm{x}$ PBST.

9. Wash the membrane 3 times for 10 minutes with 1xPBST and detect ADP-ribosylated proteins by ECL.

Detection of $A R T$ Auto-ribosylation using radioactive $N A D^{+}$ 
This protocol is essentially the same as described in Section 3.1.1. with the exception that streptavidin-conjugated $\mathrm{NAD}^{+}$is substituted for radioactive $\mathrm{NAD}^{+}$and detection of $\mathrm{ADP}$ ribosylated proteins is detected by autoradiography. All stated concentrations are used as final concentration in the reaction.

1. Set up a $20 \mu \mathrm{l}$ reaction on ice in $1 \mathrm{xADP}$-ribosylation buffer including $100 \mathrm{nM}{ }^{32} \mathrm{P}_{-} \mathrm{NAD}^{+}$ either with or without $5 \mu \mathrm{g} / \mathrm{ml}$ of sheared salmon sperm DNA to activate the enzymatic activity of the ART. Add $1 \mu \mathrm{M}$ of recombinant ART to the mix to start the reaction.

2. Incubate the mixture at room temperature for 30 minutes.

3. Quench the reaction by adding an equal volume of 2xSDS loading buffer and incubate at $70^{\circ} \mathrm{C}$ for 10 minutes. This condition of protein denaturation was used to minimise the risk of spilling the radioactive probe due to overheating. Alternatively, insert a very small hole in the lid of the Eppendorf tube containing the radioactive sample using a needle prior to adding 2xSDS loading buffer and boil it for 5 minutes with a lead pig above the tube to shield the radioactivity.

4. Centrifuge the sample and subject the proteins to SDS-PAGE using gels with the appropriate concentration of acrylamide depending on the molecular weight of the ART (see section 3.1.1.).

5. Place the gel on Whatman paper and cover with cling film, smoothing out as many wrinkles as possible. Vacuum dry the gel for 1 hour at $80^{\circ} \mathrm{C}$, or longer if required, and detect the auto-ribosylated proteins by autoradiography (see Note 3).

\subsubsection{ART-mediated ADP-ribosylation of substrates in vitro}

Investigation of ADP-ribosylation of substrates is performed and processed similar to detecting auto-ribosylation described above, with the exception that the substrate being tested is added to the reaction mixture prepared in step 1 of the protocols described in 3.1.1. Inclusion of biotin-conjugated or radioactive $\mathrm{NAD}^{+}$allows detection of the modified substrate 
following SDS-PAGE and Western blotting or autoradiography respectively. The amount of substrate included in the reactions can vary and needs to be determined experimentally, although we have found that $100 \mathrm{ng}$ of protein is usually sufficient. The resolution of SDSPAGE needs to be adjusted by altering the concentration of acrylamide in gels depending on the molecular weight of the substrate. The use of recombinant proteins mutated at potential ADP-ribosylation sites can be compared with wild-type proteins in these assays to assess whether a specific site of ADP-ribosylated by a given ART.

\subsubsection{Differentiate between mono and poly-ADP-ribosylation in vitro}

Whilst poly-ADP-ribosylation was the original modification identified to be catalysed by ARTs, more recently it has become apparent that the majority of these enzymes catalyse mono-ADP-ribosylation $[3,27]$. The ability of a given ART to catalyse mono- or poly-ADPribosylation, either in cis or in trans, can be defined by assessing whether the modification is removed by enzymes that degrade poly-ADP-ribose chains (PARG) $[28,29]$, or mono-ADPribose moieties (MacroD1) [30-32]. An alternative technique is to assess whether the modified substrate is recognised by ADP-ribose interaction domains that specifically recognise poly-ADP-ribose chains or mono- and poly-(ADP-ribose) structures (Pan-ADPribose).

\section{Differential degradation of ADP-ribose modifications using MacroD1 and PARG}

This technique is very similar to those described in Section 3.1.1, with the exception that the ADP-ribosylation is terminated prior to addition of enzymes that remove ADP-ribose modifications. Enzymes that remove either mono-ADP-ribose (MacroD1) or Poly-ADP-ribose (PARG) are then added to the reaction prior to resolution and detection of proteins by SDSPAGE and Western blotting. The removal of the modification by either MacroD1 or PARG indicates whether the protein is MARylated or PARylated respectively. 
1. Set up a $20 \mu \mathrm{l}$ reaction on ice in 1XADP-ribosylation buffer including $25 \mu \mathrm{M}$ Biotinylated $\mathrm{NAD}^{+}$either with or without $5 \mu \mathrm{g} / \mathrm{ml}$ of sheared salmon sperm DNA to activate the enzymatic activity of the ART. Add the substrate of interest (if being analysed) followed by recombinant ART $(1 \mu \mathrm{M})$ to start the reaction.

2. Incubate the mixture at room temperature for 30 minutes.

3. Terminate the ADP-ribosylation reaction by adding $10 \mathrm{mM}$ of the ART inhibitor 3aminobenzamide.

4. Add $0.4 \mu \mathrm{M}$ MacroD1 protein or $9 \mathrm{nM}$ PARG enzyme to separate reactions and incubate at $37^{\circ} \mathrm{C}$ for 30 minutes.

5. Quench the reaction by adding an equal volume of 2xSDS loading buffer and boil the mixture for 5 minutes.

6. Assess the ADP-ribosylation status by Western Blot as described in 3.1.1.

\section{Differential detection of modifications using ADP-ribose recognition domains}

In this assay, ADP-ribosylation assays are performed as in Section 3.1.1, with the exception that only unlabelled $\mathrm{NAD}^{+}$is included in reactions. Following SDS-PAGE, ADP-ribosylated proteins are detected by employing reagents that bind either poly-ADP-ribose or pan-ADPribose (i.e. both mono- and poly-(ADP-ribose) structures). Recognition of the substrate by both pan- and poly-ADP-ribose binding reagents indicates poly-ADP-ribosylation, whilst recognition by exclusively pan-ADP-ribose binding reagent indicates mono-ADP-ribosylation.

1. Set up a $20 \mu \mathrm{l}$ reaction on ice in 1XADP-ribosylation buffer including an additional $25 \mu \mathrm{M}$ $\mathrm{NAD}^{+}$either with or without $5 \mu \mathrm{g} / \mathrm{ml}$ of sheared salmon sperm DNA to activate the enzymatic activity of ART. Add the substrate (if being analysed) followed by $1 \mu \mathrm{M}$ recombinant ART to start the reaction.

2. Incubate the mixture at room temperature for 30 minutes. 
3. Quench the reaction by adding an equal volume of 2xSDS loading buffer and boil the mixture for 5 minutes.

4. Separate the sample using SDS-PAGE. The percentage of acrylamide in the gel depends on the molecular weight of the substrate and/or ART being analysed (see section 3.1.1).

4. Block the membrane with $5 \%$ milk in $1 \times$ TBST for 1 hour at room temperature.

5. Incubate the membrane with poly-ADP-ribose binding reagent (Millipore; MABE1031), which recognizes poly-ADP ribose chains, or pan-ADP-ribose binding reagent (Millipore; MABE1016), which binds to mono- and poly- ADP ribose chains, in 5\% milk in 1xTBST for 1 hour at room temperature (see Note 6).

6. Wash the membrane 3 times for 10 minutes with 1 xTBST.

7. Incubate the membrane with anti-rabbit secondary antibody in 5\% milk in 1xTBST for 1 hour at room temperature.

8. Wash the membrane 3 times for 10 minutes each with 1 XTBST and detect ADPribosylated protein by ECL.

\subsection{ADP-ribosylation detection in vivo}

Whilst the analysis of ADP-ribosylation events in vitro can inform on potential targets for a given ART, in addition to the sites on the protein modified, it is important to assess whether these events similarly occur in vivo. Reagents that recognise proteins only when modified with poly-ADP-ribose chains or mono-ADP-ribose moieties allow the detection of ADPribosylation events in vivo either directly by immuno-fluorescence microscopy, or by western blotting following fractionation of cellular compartments or purification of proteins. Given our interest in DNA damage responsive ARTs, we describe procedures to assess ADPribosylation events associated with DNA damage using microscopy to assess nuclear ADPribosylation, or biochemical fraction of chromatin and histones from cells. However, these 
techniques are easily transferable to other cellular fractionation and protein purification procedures, broadening the use of these approaches to other biological contexts.

\subsubsection{Immunofluorescence}

Immuno-fluorescence is a commonly used technique to assess the cellular localisation of proteins. It is a particularly powerful technique to assess the accumulation of DNA repair proteins into punctate nuclear foci following DNA damage, an observation that reflects the accumulation of DNA repair factors at DNA damage sites. This technique works particularly well when employing reagents that recognise post-translational modifications, including reagents that recognise ADP-ribosylated proteins (Figure 1). Cells are left untreated or exposed to the appropriate DNA damaging agent. Prior to fixing cells a mild detergent extraction is employed to reduce the background signal, revealing extraction resistant signals that represent modifications at sites of DNA damage. ADP-ribosylation is subsequently detected by immunofluorescence using either ADP-ribosylation specific antibodies, or ADP-ribose interaction domains that specifically recognise poly-ADP-ribose chains or mono- and poly-(ADP-ribose) structures (Pan-ADP-ribose).

\section{Preparation of coverslips}

1. Dilute exponentially growing Dictyostelium cells to $1 \times 10^{6} \mathrm{cells} / \mathrm{ml}$ in $\mathrm{HL} 5$ and add $1 \mathrm{ml}$ of cells to each well of a 24-well plate, with each well containing a clean, uncoated coverslip. Allow cells to settle on coverslips for 1 hour, followed by washing the coverslips gently with $1 \mathrm{ml} \mathrm{HL5}$ to remove non-adherent cells.

2. Incubate the cells in the 24-well plate with a DNA damaging agent. The optimum concentration and incubation time to induce ADP-ribosylation differs between DNA damaging agents and needs to be experimentally determined. A guide to DNA damaging agents employed in Dictyostelium is provided in Table 1. 
3. Place the coverslip cell-side up on Parafilm and incubate it for 5 minutes with NEB-IF (do not let the coverslip dry out at any stage and add and remove liquid with care). For a $10 \mathrm{~mm}$ diameter coverslip, 40-60 $\mu \mathrm{L}$ liquid is sufficient (see Note 4).

4. Transfer the coverslip into a fresh well of a 24 well plate containing $1 \mathrm{~mL}$ of $1 x$ TBS.

5. For the fixation of cells, remove the $1 \mathrm{x}$ TBS and add $1 \mathrm{ml} 70 \%$ ethanol to the 24 well plate and incubate it for 5 minutes, followed by rinsing with $100 \%$ methanol.

6. Gently rinse the coverslip three times with $1 \mathrm{~mL} 1 \times$ TBS in the 24 well plate. At this stage, coverslips can be stored for up to 4 days at $4^{\circ} \mathrm{C}$ in $1 \mathrm{~mL}$ of $1 \times$ TBS and processed later.

\section{Immuno-detection}

1. Transfer coverslips cell-side-up to fresh Parafilm and incubate with blocking solution for 1 hour at room temperature.

2. Gently replace the blocking solution with antibody solution containing the appropriate ADP-ribose detection reagent. Incubate the coverslip for 1 hour at room temperature.

3. Transfer coverslips to a fresh 24 well plate and gently rinse three times in $1 \mathrm{ml}$ of $1 \mathrm{x}$ TBS.

4. Transfer coverslips, cell side up, to fresh Parafilm and incubate with antibody solution containing secondary antibody for 1 hour at room temperature in the dark.

\section{Repeat washing as in Step 3.}

6. Transfer the coverslips, cell side down, onto a glass slide containing a small volume of mounting media with DAPI and seal the edges of the coverslip with clear nail polish. Allow nail polish to dry for around 30 minutes before microscopy analysis. Coverslips can be stored at $4^{\circ} \mathrm{C}$ in the dark but the signal will fade with time.

7. Approximately 200 cells are counted per condition in three independent experiments. Cells, that show staining over the untreated control are considered as 'positive' and may be 
categorised based on the level of staining. The percentage of 'positive' nuclei is determined as proportion of the total number of counted nuclei (visualized by DAPI)

\subsubsection{Chromatin extraction}

The ADP-ribosylation of chromatin-associated proteins can also be monitored by Western blot. In this protocol, cells are left untreated or exposed to an appropriate DNA damaging agent. A relatively straightforward cellular fractionation procedure is employed to isolate cytosol, nucleosol and chromatin fractions from cells (Figure 2). Analysis of chromatin fractions by SDS-PAGE and Western blotting using reagents that detect ADP-ribosylation is able to detect ADP-ribosylated proteins in chromatin.

The following protocol is modified from [12]. It is important to note that poly-ADP-ribosylation is a highly dynamic post-translational modification that can be removed by PARG. Additionally, DNA fragmentation during the extraction procedure can result in activation of DNA damage responsive ARTs. Therefore, an important addition to these procedures is the inclusion of ART and PARG inhibitors in extraction buffers to prevent ectopic activation of ARTs and removal of PAR chains during the fractionation procedure.

1. Collect $1.5 \times 10^{7}$ exponentially growing cells, spin them down at $1500 x g$ for 3 minutes and resuspend in $\mathrm{HL} 5$ at $5 \times 10^{6}$ cells $/ \mathrm{ml}$.

2. Treat cells with a DNA damaging agent whilst gently agitating. The optimum concentration and incubation time differs between DNA damaging agents and needs to be experimentally determined (see Table 1).

3. Following the treatment, collect the cells by spinning at $1500 \mathrm{xg}$ for 3 minutes and wash them with $1 \mathrm{ml}$ of ice cold KK2. 
4. Gently resuspend pellet in ice cold NLB* supplemented with $0.1 \%$ Triton X-100 to a final density of $5 \times 10^{6}$ cells $/ \mathrm{ml}$ and incubate for 15 minutes at $4^{\circ} \mathrm{C}$.

5. Centrifuge at $14,000 \mathrm{xg}$ for 3 minutes at $4^{\circ} \mathrm{C}$ to gain a pellet, $\mathrm{P} 1$, and supernatant fraction, S1. S1 can be discarded or retained for subsequent analysis.

6. Repeat steps 4 and 5 with pellet P1.

7. Gently resuspend pellet P1 in the same volume of $\mathrm{NLB}^{*}$ as used in steps 4 supplemented with $200 \mu \mathrm{g} / \mathrm{ml}$ RNaseA and incubate while rotating at room temperature for 30 minutes.

8. Centrifuge at $14,000 \mathrm{xg}$ for 3 minutes at $4^{\circ} \mathrm{C}$ to gain a pellet, $\mathrm{P} 2$, and supernatant fraction, S2. Pellet P2 is the detergent insoluble fraction, and includes chromatin and its associated proteins (see Note 5).

9. Resuspend P2 in 1x SDS loading buffer and analyse fractions by Western blot. When $1.5 \times 10^{7}$ cells were used, P2 can be resuspended in $80 \mu \mathrm{l}$ of SDS loading buffer and typically $10 \mu \mathrm{l}$ were used for western blot analysis. However, the volume of SDS loading buffer can vary according to the protein of interest and the ease of detection by Western blot. A control Western blot is required to confirm equal loading of chromatin, which can be done using an antibody against a histone protein (e.g. histone H3) or actin. Instead of primary antibodies, a-poly-ADP-ribose binding reagent or $\alpha$-pan-ADP-ribose binding reagent can be used to detect either mono and poly or only mono ADP-ribosylation. Preparation and processing is similar to a conventional western blotting when using ADP-ribose binding reagents and is described in 3.1.3.

\subsubsection{Histone acid extraction}

Histones are an important component of chromatin modified by ARTs [33]. Whilst ADPribosylated histones will co-fractionate with chromatin using the techniques described in Section 3.2.2, it is also possible to specifically analyse the ADP-ribosylation status of these proteins using an optimised acid-extraction protocol developed to enrich Dictyostelium 
histones from vegetative cells [22,13]. Essentially, following exposure of cells to DNA damage, chromatin is isolate from cells using a protocol similar to that described in Section 3.2.2. However, these samples are subsequently subjected to an acid extraction step that extracts histone proteins from the chromatin, resulting in a histone-enriched sample. Following resolution of histone extracts by SDS-PAGE, ADP-ribosylation events can be analysed by Western blot (Figure 3).

1. Collect $2-1 \times 10^{8}$ exponentially growing cells and centrifuge them at $1500 x g$ for 3 minutes. Resuspend cells in HL5 at a concentration of $1 \times 10^{8}-5 \times 10^{7}$ cells $/ \mathrm{ml}$.

2. Treat cells with the DNA damaging agent whilst gently agitating.

3. Following the treatment, collect the cells by spinning at $1500 \mathrm{xg}$ for 3 minutes. Resuspend the cell in $2 \mathrm{~mL}$ ice cold $\mathrm{KK} 2$ and repeat the centrifugation step.

4. Gently resuspend the pellet in NEB-HAE, containing ART and PARG inhibitors, to a final density of $1 \times 10^{8} \mathrm{cells} / \mathrm{ml}$. Incubate with rotation for 15 minutes at $4^{\circ} \mathrm{C}$ to promote hypotonic swelling and cell lysis by mechanical shearing.

5. Centrifuge at $2,300 x g$ for 5 minutes to give rise to a pellet containing the nuclei, $\mathrm{P} 1$, and a supernatant fraction, $\mathrm{S} 1 . \mathrm{S} 1$ can be discarded or retained for subsequent analysis.

6. Gently resuspend $P 1$ in the same volume of NEB-HAE containing $4 M$ urea and $2 \% \beta-$ mercaptoethanol as used in step 4 and incubate while rotating at $4^{\circ} \mathrm{C}$ for 15 minutes.

\section{Repeat step 5}

8. Gently resuspend $\mathrm{P} 1$ in $0.4 \mathrm{M} \mathrm{HCl}$ at a density of $5 \times 10^{8}$ cell $/ \mathrm{ml}$ and incubate on a rotating wheel overnight at $4^{\circ} \mathrm{C}$.

9. Harvest acid extracted histones by centrifugation at $16000 \mathrm{xg}$ for 15 minutes at $4^{\circ} \mathrm{C}$ which gives rise to a supernatant, $\mathrm{S} 2$, containing the histones and a pellet, $\mathrm{P} 2$, containing cell debris. 
10. Precipitate the histones by adding 6.5 volumes of acetone to $S 2$ and invert the tube several times. Incubate the sample at $-20^{\circ} \mathrm{C}$ for 2 hours.

11. Centrifuge at $16000 \mathrm{xg}$ for 15 minutes at $4^{\circ} \mathrm{C}$ to give rise to a pellet, $\mathrm{P} 3$, containing precipitated histones and a supernatant S3.

12. Carefully remove the supernatant and wash P3 twice with ice-cold acetone without disturbing the pellet, centrifuge as described in step 11. The acetone is used to remove the acid from the solution without dissolving the histone pellet.

13. Carefully remove the supernatant and air dry the pellet in the fume hood for 20 minutes.

14. Resuspend the pellet in $8 \mathrm{M}$ urea supplemented with $5 \% \beta$-mercaptoethanol.

15. Samples can be diluted with SDS loading buffer and the PARylation status of acid extracted histones analysed by western blotting using ADP-ribose binding reagents as described in Section 3.1.3.

\subsection{Functional analysis of ADP-ribosylation events}

The ability to perform gene disruption and replacement strategies using targeted-HR in Dictyostelium make this a powerful system to assess the functional consequences of disrupting specific ADP-ribosylation events. Generating gene knockouts is relatively straightforward in Dictyostelium and we have made strains disrupted in specific ARTs to define which enzymes are required to mediate ADP-ribosylation events in response to genotoxic stress $[11,12,15]$. Methods to generate Dictyostelium gene disruption strains have been described in detail elsewhere $[34,35]$. Therefore, in this section we focus on techniques to define ADP-ribosylation sites in vivo, including knocking-in mutations at ADP-ribosylation sites using gene replacement technologies.

\subsubsection{Expression and purification of recombinant proteins}


Putative ADP-ribosylation sites on target proteins can be identified in vitro (Section 3.1.2) and recent advances in mass spectrometry have begun to define the ADP-ribosylome [3643]. In both instances, it is important to verify ADP-ribosylation sites by mutating the specific amino acids modified on the protein to confirm this abrogates ADP-ribosylation in vivo. One way this can be achieved is by expressing recombinant proteins mutated a putative ADPribosylation sites and comparing their modification status relative to wild-type controls. The inclusion of an epitope tag onto the recombinant proteins can facilitate this analysis, either by inducing a shift in the molecular weight of the protein to distinguish it from its endogenous counterpart during Western blot analysis, or to allow immuno-purification of the recombinant proteins (for example see [13]). Given inclusion of an epitope tag may interfere with the modification status of a protein, depending on its location, it is recommended that this analysis is performed with both C-terminal and $\mathrm{N}$-terminal tagged proteins. Performing this analysis is a relatively straightforward way to confirm ADP-ribosylation sites prior to committing to knocking in mutations at the relevant endogenous loci.

This methodology first requires cloning of the gene of interest, either wild-type or mutated at putative ADP-ribosylation sites, into the pDXA-3C expression vector downstream of a constitutive actin15 promoter [24,25]. The vector also contains the Dictyostelium Ddp2 origin of replication (ORI), conferring the cis functions for extrachromosomal replication. Expression of pDXA-3C vector requires the co-transfection with the helper plasmid pREP conferring the Ddp2 ORI trans replication function [24,25]. pDXA-3C also contains a neomycin resistance gene. Therefore, following transfection of cells with pDXA-3C and pREP, incubation in G418 will select for cells that retain the vectors and thus express the gene of interest. A comparison of the ADP-ribosylation status of the recombinant wild-type and mutant proteins can be monitored by employing methods described in Sections 3.2.3 and 3.2.2. 
1. The pDXA-3C vector contains an ATG start codon upstream of the multiple cloning site. The cloning strategy should be designed to insert the gene of interest and associated epitope tag in frame with this codon. Amplify the entire gene of interest by PCR from AX2 genomic DNA. To facilitate cloning into the pDXA-3C expression vector the forward primer contains an appropriate restriction enzyme, as for example Kpnl, followed by a Myc tag on its $5^{\prime}$ end that is in the same reading frame as the gen of interest. The reverse Primer should contain another appropriate restriction enzyme site to allow insertion of the gene into pDXA3C. The inclusion of the Myc-tag ensures detecting via western blotting using a Myc antibody.

2. Subclone the amplified DNA fragment first into PJET 1.2 and confirm insertion of the PCR product by restriction enzyme analysis and accuracy of the PCR amplification by DNA sequencing using the appropriate primer (pJET cloning kit contains primers flanking the insertion site that can be used for sequencing).

3. Introduce mutations in the potential ADP-ribosylation sites using the QuickChange sitedirected mutagenesis kit with primers containing the desired mutation in the centre, each complementary to opposite strands of the vector. Confirm the introduction of the relevant mutation by DNA sequencing.

4. Excise the gene of interest containing the mutation with appropriate restriction enzymes from pJET 1.2 and insert it into the extrachromosomal vector pDXA-3C in frame with the ATG start codon present in the vector. This should also be performed with the control wildtype gene.

5. Transfect Ax2 cells by electroporation with 2-4 $\mu \mathrm{g}$ of the extrachromosomal vector along with $1 \mu \mathrm{g}$ of the helper plasmid pREP in H50 buffer using standard procedures [35]. As a control, transfect Ax2 cells with pDXA-3 containing the wild-type gene of interest. This is necessary to compare the ADP-ribosylation status of the mutated and non-mutated protein. Transfer the transfected cells in a $10 \mathrm{~cm}$ dish and add $10 \mathrm{ml}$ of HL5. The pDXA3C vector 
contains a G418-resistance cassette to allow gene expression and selection of transfected cells. The next day add $10 \mu \mathrm{g} / \mathrm{ml} \mathrm{G} 418$ to select for cells that have taken up the vector.

6. Once cells become confluent, approximately 5-7 days after the transfection, transfer them into flasks and passage them for another $2-4$ days in media containing $10 \mu \mathrm{g} / \mathrm{ml} \mathrm{G418} \mathrm{to}$ maintain the selection process.

7. Check the expression level of the Myc-tagged protein by Western blotting. Whole cell extracts are prepared by pelleting $5 \times 10^{6}$ cells at $1500 x g$ for 3 minutes. Wash cells by resuspending in $1 \mathrm{ml} \mathrm{KK2}$ before pelleting again at 1500xg for 3 minutes. Discard the supernatant and resuspend the cell pellet in $30 \mu \mathrm{l} 2$ xSDS loading buffer. Boil the sample for 5 minutes and resolve $5 \mu$ l of the sample by SDS-PAGE to assess recombinant protein expression levels by Western blotting with a Myc-antibody.

8. Investigate the ADP-ribosylation status of the mutated and non-mutated proteins by performing histone acid extraction (section 3.2.3) or chromatin preparation (section 3.2.2) and analysis by western blotting (section 3.1.3).

\subsubsection{Mutation of ADP-ribosylation sites at endogenous loci}

Using gene replacement strategies to knock-in mutations at ADP-ribosylation sites in the endogenous loci makes it possible to generate ADP-ribosylation null versions of a given protein, enabling the phenotypic consequences of this mutation to be assessed. The ability to perform gene disruption and replacement strategies in Dictyostelium make this an attractive system to perform these experiments. This is exemplified by the study of histones. The high copy number arrays of histone genes in vertebrates makes it difficult to genetically manipulate these loci. In contrast, Dictyostelium contains single copies of most histone genes, making their genetic manipulation relatively straightforward $[22,23,13]$. 
The techniques below describe procedures to generate strains disrupted in site-specific mutations at ADP-ribosylation sites (for example see Figure 4). Whilst we focus on the analysis of histone genes, this approach can be employed for other substrates modified by ARTs. Essentially, this methodology involves generating a gene replacement cassette that contains the gene of interest, but with point mutations at putative ADP-ribosylation sites. The gene also contains genomic DNA sequences that flank the gene to allow site-specific recombination at the desired locus, thus replacing the wild type gene with the mutated version. A blasticidin resistance cassette is also engineered into the gene replacement cassette to allow for selection of recombinant strains. Following transfection and selection for recombinant strains, the appropriate gene disruption in selected clones is confirmed by PCR. Having isolated strains with mutations at specific sites within a gene, the impact of ADPribosylation of the protein can be assessed using methodologies described in Section 3.2 and the impact of a variety of cellular phenotypes assessed.

1. To generate a knock-in mutation use PCR to amplify the entire coding sequence of the gene of interest in addition to $1 \mathrm{~kb}$ of flanking genomic DNA 5'and $3^{\prime}$ to the gene.

2. Subclone the entire amplified fragment into pJET 1.2 and confirm the integrity of the PCR by DNA sequencing.

3. Excise the selection marker (BSR cassette) from the vector pLPBLP [44] using Smal and insert it into a region of the amplified fragment 3' to the gene of interest using an appropriate blunt end restriction enzyme site. It is important to insert the selection marker into an inert region of the genome and not disrupt any promoter region or gene which might be downstream of the gene being studied. Therefore, insert the BSR cassette $20-200 \mathrm{bp}$ after the stop codon. This also guarantees that $0.7-1 \mathrm{~kb}$ of the 3'region of the amplified fragment is still downstream of the selection marker to facilitate gene replacement of the endogenous gene by targeted homologous recombination. 
Note: If the only restriction enzyme sites available in the 3'region of the gene are facilitating DNA overhangs, mediate DNA end blunting using standard protocols (using Klenow fragment or Mung Bean Nuclease). If there is no restriction enzyme site available, introduce a blunt end restriction enzyme site using the QuikChange method.

7. Introduce the desired mutations using the QuikChange method. If possible, also introduce a novel restriction enzyme site without changing the encoded amino acid sequence to facilitate screening of mutants.

9. Verify the introduced mutation(s) by DNA sequencing.

10. Excise the targeting construct containing the mutated gene, BSR cassette and flanking genomic DNA sequences from the vector using appropriate restriction enzymes. Purify the DNA fragment using Phenol Chloroform extraction.

11. Transfect the Ax2 cells by electroporation with $4-8 \mu \mathrm{g}$ of the targeting construct in $\mathrm{H} 50$ buffer. Following the transfection prepare serial dilutions with $1 \times 10^{5}, 1 \times 10^{4}$ and $1 \times 10^{3} \mathrm{cells} / \mathrm{ml}$ and transfer them into 96-well plates. The aim is to achieve a dilution that following selection in blasticidin will result in a single colony in a well, ensuring a clonal strain. The next day, add $10 \mu \mathrm{g} / \mathrm{ml}$ blasticidin and select cultures for approximately two weeks until colonies are apparent.

12. Transfer blasticidin resistant clones into a 24-well plate and expand by culturing in selection for another 2 days.

13. Verify gene replacement using PCR to amplify the segment of the gene of interest spanning the mutated site and confirming mutation by DNA sequencing. If a novel restriction enzyme site was introduced in the mutation strategy the PCR fragment can be initially screened by assessing whether the PCR fragments are cleaved by the appropriate restriction enzyme. 
14. Once a strain containing the desired mutations has been identified, re-clone the strain by spreading the cells on a KA lawn on SM Agar [34]. After 3-4 days pick single colonies and expand under standard growth conditions.

15. Repeat step 13 to confirm that the selected clonal strains contain the desired mutation.

\section{NOTES}

Note 1: The reaction setup of all ART ADP-ribosylation assays should be carried out on ice to avoid initiation of the catalytic activity of the ART enzymes prior to the experiment. Also, sheared salmon sperm DNA and NAD should be gently defrosted on ice.

Note 2: Quenched samples of the ART ADP-ribosylation assays can be stored at $-20^{\circ} \mathrm{C}$ before analysing them by SDS PAGE.

Note 3: Before adding the X-ray film in the dark in Section 3.1.1.2, check the radioactive signal of the gel, especially at around the size of the ART, using a Geiger counter to confirm ADP-ribosylation using ${ }^{32} \mathrm{P}-\mathrm{NAD}$. Incubate the cassette containing the film and the gel for 2448 hours and store it in a $-80^{\circ} \mathrm{C}$ freezer to increase the signal. Incubation with the X-ray film can be repeated and shortened or extended depending of the signal intensity/radioactivity.

Note 4: Coverslips should never be allowed to dry out. To ensure this, coverslips can be processed in small batches. Furthermore, during antibody incubation on Parafilm the coverslips should be covered with the base of the 24 well plate so that each coverslip is contained within one well. Blocking and antibody solutions should cover the entire coverslip during the incubation steps whilst being restricted to the coverslip by surface tension (40$60 \mu \mathrm{L}$ is sufficient for a $10 \mathrm{~mm}$ diameter coverslip). At all stages, coverslips should be treated gently when adding or removing liquid to minimise loss of cells. 
Note 5: The pellets that occur during chromatin extraction and histone extraction can be very small and might appear transparent. Be careful when removing the supernatant after spinning to avoid losing the pellet and to minimise loss of cells.

Note 6: Blocking, as well as incubation with the primary antibody can be carried out at room temperature for 1 hour or overnight at $4^{\circ} \mathrm{C}$ during western blotting, as determined during antibody optimisation or according to the manufacturers' instructions.

\section{ACKNOWLEDGEMENTS}

We thank members of the Lakin and Pears laboratories for constructive comments during the preparation of this manuscript. NL's laboratory is supported by Cancer Research UK (www.cancerresearch.org.uk; grant C1521/A12353), Medical Research Council (www.mrc.ac.uk; MR/L000164/1) and NC3Rs (www.nc3rs.org.uk; NC/K00137X/1). AR was supported by a Clarendon Award (University of Oxford). CP's laboratory is supported by NC3Rs (www.nc3rs.org.uk; NC/M000834/1).

\section{REFERENCES}

1. Citarelli M, Teotia S, Lamb RS (2010) Evolutionary history of the poly(ADP-ribose) polymerase gene family in eukaryotes. BMC Evol Biol 10:308. doi:1471-2148-10-308 [pii] $10.1186 / 1471-2148-10-308$

2. Otto H, Reche PA, Bazan F, Dittmar K, Haag F, Koch-Nolte F (2005) In silico characterization of the family of PARP-like poly(ADP-ribosyl)transferases (pARTs). BMC Genomics 6:139. doi:1471-2164-6-139 [pii]

$10.1186 / 1471-2164-6-139$ 
3. Vyas S, Matic I, Uchima L, Rood J, Zaja R, Hay RT, Ahel I, Chang P (2014) Family-wide analysis of poly(ADP-ribose) polymerase activity. Nat Commun 5:4426.

doi:10.1038/ncomms5426

4. Block WD, Lees-Miller SP (2005) Putative homologues of the DNA-dependent protein kinase catalytic subunit (DNA-PKcs) and other components of the non-homologous end joining machinery in Dictyostelium discoideum. DNA Repair (Amst) 4 (10):1061-1065. doi:S1568-7864(05)00127-8 [pii]

10.1016/j.dnarep.2005.06.008

5. Hsu DW, Gaudet P, Hudson JJ, Pears CJ, Lakin ND (2006) DNA damage signaling and repair in Dictyostelium discoideum. Cell Cycle 5 (7):702-708. doi:2626 [pii] 6. Hudson JJ, Hsu DW, Guo K, Zhukovskaya N, Liu PH, Williams JG, Pears CJ, Lakin ND (2005) DNA-PKcs-dependent signaling of DNA damage in Dictyostelium discoideum. Curr Biol 15 (20):1880-1885. doi:S0960-9822(05)01109-7 [pii]

10.1016/j.cub.2005.09.039

7. Muramoto T, Chubb JR (2008) Live imaging of the Dictyostelium cell cycle reveals widespread S phase during development, a G2 bias in spore differentiation and a premitotic checkpoint. Development 135 (9):1647-1657. doi:dev.020115 [pii]

10.1242/dev.020115

8. Zhang XY, Langenick J, Traynor D, Babu MM, Kay RR, Patel KJ (2009) Xpf and not the Fanconi anaemia proteins or Rev3 accounts for the extreme resistance to cisplatin in Dictyostelium discoideum. PLoS Genet 5 (9):e1000645. doi:10.1371/journal.pgen.1000645 9. Pontel LB, Langenick J, Rosado IV, Zhang XY, Traynor D, Kay RR, Patel KJ (2016) Xpf suppresses the mutagenic consequences of phagocytosis in Dictyostelium. J Cell Sci 129 (24):4449-4454. doi:10.1242/jcs. 196337 
10. Pears CJ, Couto CA, Wang HY, Borer C, Kiely R, Lakin ND (2012) The role of ADPribosylation in regulating DNA double-strand break repair. Cell Cycle 11 (1):48-56. doi:18793 [pii]

10.4161/cc.11.1.18793

11. Couto CA, Hsu DW, Teo R, Rakhimova A, Lempidaki S, Pears CJ, Lakin ND (2013) Nonhomologous end-joining promotes resistance to DNA damage in the absence of an ADP-ribosyltransferase that signals DNA single strand breaks. J Cell Sci $126(\mathrm{Pt}$ 15):34523461. doi:10.1242/jcs.128769

jcs.128769 [pii]

12. Couto CA, Wang HY, Green JC, Kiely R, Siddaway R, Borer C, Pears CJ, Lakin ND (2011) PARP regulates nonhomologous end joining through retention of Ku at double-strand breaks. J Cell Biol 194 (3):367-375. doi:jcb.201012132 [pii]

10.1083/jcb.201012132

13. Rakhimova A, Ura S, Hsu DW, Wang HY, Pears CJ, Lakin ND (2017) Site-specific ADPribosylation of histone H2B in response to DNA double strand breaks. Sci Rep 7:43750. doi:10.1038/srep43750

14. Ahel I, Ahel D, Matsusaka T, Clark AJ, Pines J, Boulton SJ, West SC (2008) Poly(ADPribose)-binding zinc finger motifs in DNA repair/checkpoint proteins. Nature 451 (7174):8185. doi:nature06420 [pii]

$10.1038 /$ nature 06420

15. Gunn AR, Banos-Pinero B, Paschke P, Sanchez-Pulido L, Ariza A, Day J, Emrich M, Leys D, Ponting CP, Ahel I, Lakin ND (2016) The role of ADP-ribosylation in regulating DNA interstrand crosslink repair. J Cell Sci 129 (20):3845-3858. doi:10.1242/jcs.193375 16. Strmecki L, Greene DM, Pears CJ (2005) Developmental decisions in Dictyostelium discoideum. Dev Biol 284 (1):25-36 
17. Robinson DN, Spudich JA (2000) Dynacortin, a genetic link between equatorial contractility and global shape control discovered by library complementation of a Dictyostelium discoideum cytokinesis mutant. J Cell Biol 150 (4):823-838

18. Chen L, lijima M, Tang M, Landree MA, Huang YE, Xiong Y, Iglesias PA, Devreotes PN (2007) PLA2 and PI3K/PTEN pathways act in parallel to mediate chemotaxis. Dev Cell 12 (4):603-614. doi:S1534-5807(07)00105-0 [pii]

10.1016/j.devcel.2007.03.005

19. Li G, Alexander H, Schneider N, Alexander S (2000) Molecular basis for resistance to the anticancer drug cisplatin in Dictyostelium. Microbiology 146 ( Pt 9):2219-2227

20. Van Driessche N, Alexander H, Min J, Kuspa A, Alexander S, Shaulsky G (2007) Global transcriptional responses to cisplatin in Dictyostelium discoideum identify potential drug targets. Proc Natl Acad Sci U S A 104 (39):15406-15411. doi:0705996104 [pii]

10.1073/pnas.0705996104

21. Williams RS, Eames M, Ryves WJ, Viggars J, Harwood AJ (1999) Loss of a prolyl oligopeptidase confers resistance to lithium by elevation of inositol $(1,4,5)$ trisphosphate. Embo J 18 (10):2734-2745. doi:10.1093/emboj/18.10.2734

22. Hsu DW, Chubb JR, Muramoto T, Pears CJ, Mahadevan LC (2012) Dynamic acetylation of lysine-4-trimethylated histone $\mathrm{H} 3$ and $\mathrm{H} 3$ variant biology in a simple multicellular eukaryote. Nucleic Acids Res 40 (15):7247-7256. doi:gks367 [pii]

10.1093/nar/gks367

23. Stevense M, Chubb JR, Muramoto T (2011) Nuclear organization and transcriptional dynamics in Dictyostelium. Dev Growth Differ 53 (4):576-586. doi:10.1111/j.1440169X.2011.01271.x

24. Leiting B, Noegel A (1988) Construction of an extrachromosomally replicating transformation vector for Dictyostelium discoideum. Plasmid 20 (3):241-248 
25. Manstein DJ, Schuster HP, Morandini P, Hunt DM (1995) Cloning vectors for the production of proteins in Dictyostelium discoideum. Gene 162 (1):129-134

26. D'Amours D, Desnoyers S, D'Silva I, Poirier GG (1999) Poly(ADP-ribosyl)ation reactions in the regulation of nuclear functions. Biochemical Journal 342 (Pt2):249-268 27. Gibson BA, Kraus WL (2012) New insights into the molecular and cellular functions of poly(ADP-ribose) and PARPs. Nat Rev Mol Cell Biol 13 (7):411-424. doi:10.1038/nrm3376 nrm3376 [pii]

28. Slade D, Dunstan MS, Barkauskaite E, Weston R, Lafite P, Dixon N, Ahel M, Leys D, Ahel I (2011) The structure and catalytic mechanism of a poly(ADP-ribose) glycohydrolase. Nature 477 (7366):616-620. doi:10.1038/nature10404

nature10404 [pii]

29. Barkauskaite E, Brassington A, Tan ES, Warwicker J, Dunstan MS, Banos B, Lafite P, Ahel M, Mitchison TJ, Ahel I, Leys D (2013) Visualization of poly(ADP-ribose) bound to PARG reveals inherent balance between exo- and endo-glycohydrolase activities. Nat Commun 4:2164. doi:10.1038/ncomms3164

30. Sharifi R, Morra R, Denise Appel C, Tallis M, Chioza B, Jankevicius G, Simpson MA, Matic I, Ozkan E, Golia B, Schellenberg MJ, Weston R, Williams JG, Rossi MN, Galehdari H, Krahn J, Wan A, Trembath RC, Crosby AH, Ahel D, Hay R, Ladurner AG, Timinszky G, Williams RS, Ahel I (2013) Deficiency of terminal ADP-ribose protein glycohydrolase TARG1/C6orf130 in neurodegenerative disease. Embo J. doi:10.1038/emboj.2013.51

emboj201351 [pii]

31. Rosenthal F, Feijs KL, Frugier E, Bonalli M, Forst AH, Imhof R, Winkler HC, Fischer D, Caflisch A, Hassa PO, Luscher B, Hottiger MO (2013) Macrodomain-containing proteins are new mono-ADP-ribosylhydrolases. Nat Struct Mol Biol 20 (4):502-507.

doi:10.1038/nsmb.2521 
32. Jankevicius G, Hassler M, Golia B, Rybin V, Zacharias M, Timinszky G, Ladurner AG (2013) A family of macrodomain proteins reverses cellular mono-ADP-ribosylation. Nat Struct Mol Biol 20 (4):508-514. doi:10.1038/nsmb.2523

33. Messner S, Hottiger MO (2011) Histone ADP-ribosylation in DNA repair, replication and transcription. Trends Cell Biol 21 (9):534-542. doi:S0962-8924(11)00106-1 [pii]

10.1016/j.tcb.2011.06.001

34. Couto AM, Lakin ND, Pears CJ (2013) Investigation of DNA repair pathway activity. Methods Mol Biol 983:295-310. doi:10.1007/978-1-62703-302-2_16

35. Faix J, Linkner J, Nordholz B, Platt JL, Liao XH, Kimmel AR (2013) The application of the Cre-loxP system for generating multiple knock-out and knock-in targeted loci. Methods Mol Biol 983:249-267. doi:10.1007/978-1-62703-302-2_13

36. Daniels CM, Ong SE, Leung AK (2014) Phosphoproteomic approach to characterize protein mono- and poly(ADP-ribosyl)ation sites from cells. J Proteome Res 13 (8):35103522. doi:10.1021/pr401032q

37. Daniels CM, Ong SE, Leung AK (2015) The Promise of Proteomics for the Study of ADP-Ribosylation. Mol Cell 58 (6):911-924. doi:10.1016/j.molcel.2015.06.012

38. Gagne JP, Isabelle M, Lo KS, Bourassa S, Hendzel MJ, Dawson VL, Dawson TM, Poirier GG (2008) Proteome-wide identification of poly(ADP-ribose) binding proteins and poly(ADP-ribose)-associated protein complexes. Nucleic Acids Res 36 (22):6959-6976. doi:gkn771 [pii]

10.1093/nar/gkn771

39. Isabelle M, Gagne JP, Gallouzi IE, Poirier GG (2012) Quantitative proteomics and dynamic imaging reveal that G3BP-mediated stress granule assembly is poly(ADP-ribose)dependent following exposure to MNNG-induced DNA alkylation. J Cell Sci 125 (Pt 19):4555-4566. doi:10.1242/jcs. 106963 
40. Jungmichel S, Rosenthal F, Altmeyer M, Lukas J, Hottiger MO, Nielsen ML (2013) Proteome-wide identification of poly(ADP-Ribosyl)ation targets in different genotoxic stress responses. Mol Cell 52 (2):272-285. doi:10.1016/j.molcel.2013.08.026

41. Zhang Y, Wang J, Ding M, Yu Y (2013) Site-specific characterization of the Asp- and Glu-ADP-ribosylated proteome. Nat Methods 10 (10):981-984. doi:10.1038/nmeth.2603 42. Bonfiglio JJ, Fontana P, Zhang Q, Colby T, Gibbs-Seymour I, Atanassov I, Bartlett E, Zaja R, Ahel I, Matic I (2017) Serine ADP-Ribosylation Depends on HPF1. Mol Cell 65 (5):932-940 e936. doi:10.1016/j.molcel.2017.01.003

43. Leidecker O, Bonfiglio JJ, Colby T, Zhang Q, Atanassov I, Zaja R, Palazzo L, Stockum A, Ahel I, Matic I (2016) Serine is a new target residue for endogenous ADP-ribosylation on histones. Nat Chem Biol 12 (12):998-1000. doi:10.1038/nchembio.2180

44. Faix J, Kreppel L, Shaulsky G, Schleicher M, Kimmel AR (2004) A rapid and efficient method to generate multiple gene disruptions in Dictyostelium discoideum using a single selectable marker and the Cre-loxP system. Nucleic Acids Res 32 (19):e143. doi:32/19/e143 [pii]

10.1093/nar/gnh136

45. Garcia MX, Alexander H, Mahadeo D, Cotter DA, Alexander S (2003) The Dictyostelium discoideum prespore-specific catalase B functions to control late development and to protect spore viability. Biochim Biophys Acta 1641 (1):55-64

46. Gaudet P, Tsang A (1999) Regulation of the ribonucleotide reductase small subunit gene by DNA-damaging agents in Dictyostelium discoideum. Nucleic Acids Res 27 (15):30423048

47. Podgorski G, Deering RA (1980) Effect of methyl methanesulfonate on survival of radiation-sensitive strains of Dictyostelium discoideum. Mutat Res 73 (2):415-418 48. Bronner CE, Welker DL, Deering RA (1992) Mutations affecting sensitivity of the cellular slime mold Dictyostelium discoideum to DNA-damaging agents. Mutat Res 274 (3):187-200 
49. Freeland TM, Guyer RB, Ling AZ, Deering RA (1996) Apurinic/apyrimidinic (AP) endonuclease from Dictyostelium discoideum: cloning, nucleotide sequence and induction by sublethal levels of DNA damaging agents. Nucleic Acids Res 24 (10):1950-1953 50. Ling AZ, Guyer RB, Deering RA (2001) Dictyostelium discoideum plasmid containing an AP-endonuclease upstream sequence: bleomycin induction of a luciferase reporter. Environ Mol Mutagen 38 (2-3):244-247

51. Deering RA, Guyer RB, Stevens L, Watson-Thais TE (1996) Some repair-deficient mutants of Dictyostelium discoideum display enhanced susceptibilities to bleomycin. Antimicrob Agents Chemother 40 (2):464-467

52. Hsu DW, Kiely R, Couto CA, Wang HY, Hudson JJ, Borer C, Pears CJ, Lakin ND (2011) DNA double-strand break repair pathway choice in Dictyostelium. J Cell Sci 124 (Pt 10):1655-1663. doi:124/10/1655 [pii]

$10.1242 / j c s .081471$

53. Lee SK, Yu SL, Alexander H, Alexander S (1998) A mutation in repB, the dictyostelium homolog of the human xeroderma pigmentosum B gene, has increased sensitivity to UVlight but normal morphogenesis. Biochim Biophys Acta 1399 (2-3):161-172. doi:S01674781(98)00103-1 [pii]

54. Hurley DL, Skantar AM, Deering RA (1989) Nuclear DNA synthesis is blocked by UV irradiation in Dictyostelium discoideum. Mutat Res 217 (1):25-32 


\section{FIGURE LEGENDS}

Figure 1. Visualisation of nuclear ADP-ribosylation by immuno-fluorescence microscopy. Ax2 cells were left untreated or exposed to $1 \mathrm{mM} \mathrm{MMS} \mathrm{and} \mathrm{processed} \mathrm{for}$ immuno-fluorescence microscopy as described in protocol 3.2.1. ADP-ribosylation was detected using an antibody that recognises proteins that are modified with poly-ADP-ribose chains.

Figure 2: Detection of ADP-ribosylated proteins in chromatin fractions prepared from cells. Schematic of the chromatin fractionation protocol is presented in (A). Fraction P2 which is both detergent and RNaseA resistant, containing chromatin and its associated proteins. ADP-ribosylated proteins can subsequently be detected by SDS-PAGE and western blot analysis using reagents that detect mono- and poly-ADP-ribosylated targets (B). This analysis can also be performed using reagents that detect other types of ADPribosylation events.

\section{Figure 3: Detection of ADP-ribosylated proteins in histone enriched fractions} prepared from cells. A. Fractionation of histones from Dictyostelium cells using an optimised acid-extraction protocol $[22,13]$. Samples were subjected to SDS-PAGE and analysed by staining with coomassie brilliant blue. B. Dictyostelium cells were left untreated or exposed to $300 \mu \mathrm{g} / \mathrm{ml}$ phleomycin for 1 hour. Chromatin or histone extracts were prepared as described in Sections 3.1.3 and 3.1.4 respectively. Samples were subjected to SDSPAGE and western blotting using the indicated antibodies.

Figure 4: Analysis of ADP-ribosylation of histones in a strain that has been mutated at E18 and E19 at the endogenous $h 2 b$ gene. Dictyostelium strains with either wild-type $h 2 b$ $\left(h 2 b^{w \downarrow}\right)$, or $h 2 b$ mutated at E18 and E19 $\left(h 2 b^{E 18 A E 19 A}\right)$ were left untreated or exposed to 300 $\mu \mathrm{g} / \mathrm{ml}$ phleomycin for 60 minutes. Histone-enriched acid extracts were prepared as 
described in protocol 3.1.4 and western blotting performed using the indicated antibodies.

Arrow heads indicate the position of ADP-ribosylated H2B protein in $h 2 b^{w t}$ but not $h 2 b^{E 18 A E 19 A}$ cells. 
Table 1: Agents used to induce different types of DNA damage in Dictyostelium.

\begin{tabular}{|c|c|c|c|}
\hline Agent & $\begin{array}{l}\text { Predominant type of DNA } \\
\text { damage }\end{array}$ & Response & Reference \\
\hline $\mathrm{H}_{2} \mathrm{O}_{2}{ }^{*}$ & Single Strand Breaks & $\begin{array}{l}\text { Sensitivity } \\
\text { Gene induction } \\
\text { ADP-ribosylation foci formation }\end{array}$ & {$[11,12,45]$} \\
\hline MMS & $\begin{array}{l}\text { Alkylated bases leading to } \\
\text { single strand breaks via } \\
\text { base excision repair* }\end{array}$ & $\begin{array}{l}\text { Gene induction } \\
\text { Sensitivity } \\
\text { ADP-ribosylation foci formation }\end{array}$ & {$[11,12,46,47]$} \\
\hline $\begin{array}{l}\text { lonising } \\
\text { radiation }\end{array}$ & $\begin{array}{l}\text { Single and Double Strand } \\
\text { Breaks }\end{array}$ & Sensitivity & {$[48,49]$} \\
\hline Bleomycin & Double Strand Breaks & $\begin{array}{l}\text { Gene induction } \\
\text { Sensitivity } \\
\text { H2AX phosphorylation } \\
\text { Cell cycle arrest }\end{array}$ & {$[6,7,48,50,51]$} \\
\hline Phleomycin & Double Strand Breaks & $\begin{array}{l}\text { Sensitivity } \\
\text { H2AX phosphorylation } \\
\text { ADP-ribosylation foci formation }\end{array}$ & {$[12,52]$} \\
\hline Cisplatin & Inter Strand Crosslinks ${ }^{*}$ & $\begin{array}{l}\text { Sensitivity } \\
\text { Gene induction }\end{array}$ & {$[8,15,19,20]$} \\
\hline
\end{tabular}




\begin{tabular}{|c|c|c|c|}
\hline & & $\begin{array}{l}\text { Resistance } \\
\text { ADP-ribosylation }\end{array}$ & \\
\hline UV radiation & Thymidine Dimers* & $\begin{array}{l}\text { Survival } \\
\text { Gene induction } \\
\text { Cell cycle arrest } \\
\text { Spore germination }\end{array}$ & {$[53,45,46,49,54]$} \\
\hline
\end{tabular}

This is far from an exhaustive list. * High doses of these agents will also lead to generation of double strand 


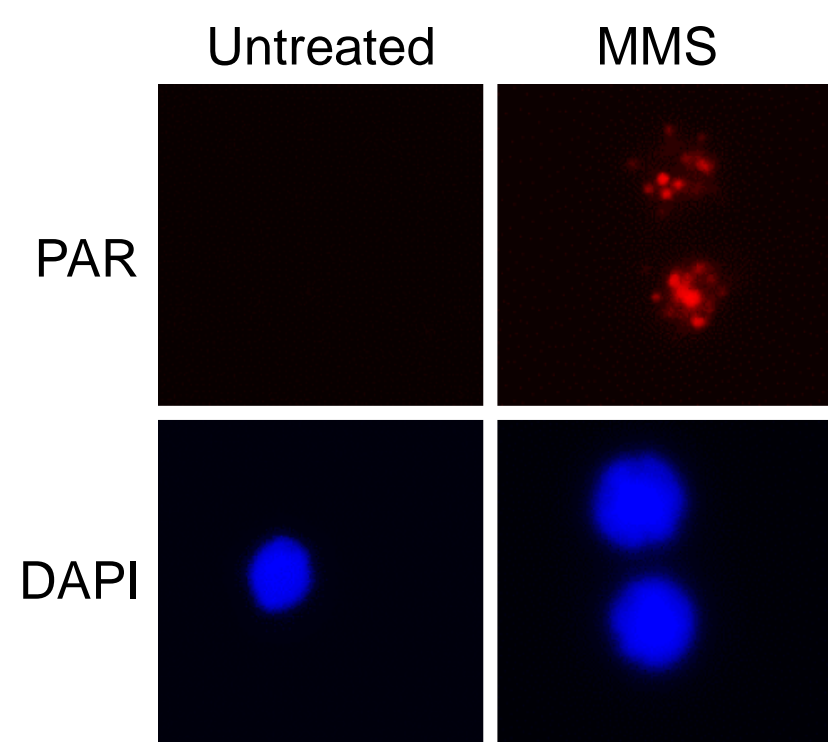

Figure 1

A

Cell and nuclear lysis

(non-ionic detergent)

$$
\text { I }
$$

$\sqrt{ }$ High speed centrifugation $\square$

S1 (detergent extractable) P2 (detergent insoluble)

I

RNase A treatment

I

$\downarrow$ High speed centrifugation $\square$

S2 (RNase A sensitive)

P2 (Rnase A resistant)
B

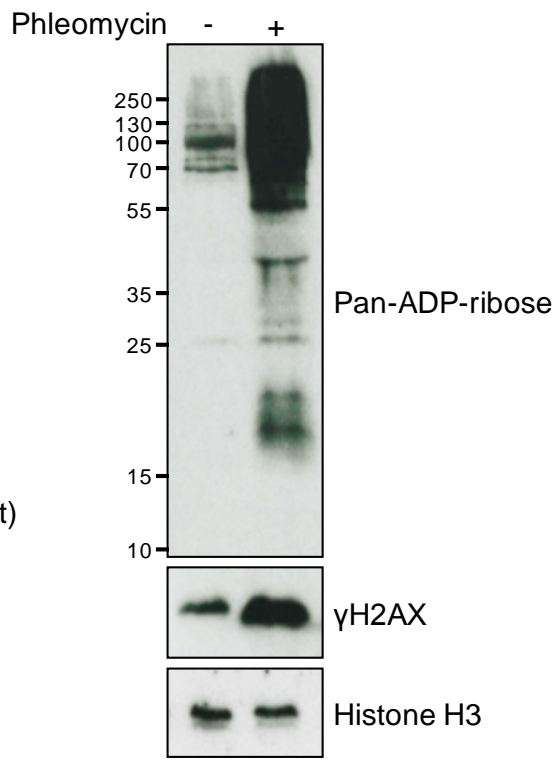

Figure 2 